\title{
Case Report: Disseminated Intravascular Coagulation as the Presenting Sign of Metastatic Prostate Cancer
}

To the Editor:--Regarding the article by Duran and Tannock, ${ }^{1}$ we would like to bring to your attention an update. We agree with the authors that solid malignancies can present in such a way, but we do not feel that this is as uncommon as suggested.

We have also had a patient with disseminated intravascular coagulation (DIC) as the initial presenting feature of metastatic prostate cancer. A 59-year-old man with persistent 2 episodes of dripping epistaxis lasting for 6 and 8 hours was found to have the features typical of DIC. At presentation, his international normalized ratio (INR) was 8, hemablobin (Hb) $137 \mathrm{~g} / \mathrm{dL}$ and his prostate specific antigen (PSA) $>1,000 \mu \mathrm{g} / \mathrm{L}$. He was treated with IV vitamin $\mathrm{K}$ where his bleeding stopped and his INR dropped to 1.9. Other presenting symptoms were general malaise, weight loss, and lumber back pain. He did not complain of any urinary symptoms. Digital rectal examination (DRE) revealed a T3/4 prostate cancer. He did not have a prostate biopsy because of his abnormal clotting but was treated with an anti-androgen (cyproterone acetate $100 \mathrm{mg}, 3$ times per day). His $\mathrm{Hb}$ steadily dropped until he was transfused at a level of 53. Once his clotting was corrected, he was converted to a luteinizing hormone releasing hormone agonist (leuprorelin).

He had an initial good response, but within 6 months had a rising PSA from a nadir of 2.4. He was converted to maximum androgen blockade with the addition of bicalutamide. However, he worsened symptomatically and his PSA continued to rise. Over a period of 23 months from diagnosis, he had combinations of hormonal manipulation, steroids, radiotherapy, and chemotherapy until he died of metastatic prostate cancer.

We would like to make the point that DIC is indeed a complication of solid malignancies and may be the presenting feature in more patients than was previously recognized. It is clear that any man presenting with DIC should be investigated for an underlying prostate cancer with a PSA and DRE.

James Hicks Southamton University Hospital, Tremona Road, Southampton, Hampshire SO16 67D, UK (e-mail: VJhicks@btopenworld.com).

\section{REFERENCE}

1. Duran I, Tannock IF. Disseminated intravascular coagulation as the presenting sign of metastatic prostate cancer. J Gen Intern Med. 2006;21 (11): 1206 .

(C) 2007 Society of General Internal Medicine 2007;22:1062 DOI: $10.1007 / \mathrm{s} 11606-007-0216-2$

Published online April 26, 2007 